\title{
USING ADVANCED COMPUTATIONAL METHODS FOR POWER GRID ANALYSIS IN METALLURGICAL INDUSTRY
}

\author{
GRYCZ Ondřej, PASKER Vit, HLAVICA Robert, FORETNÍK Pavel
}

VSB - Technical University of Ostrava, Ostrava, Czech Republic, EU, ondrej.grycz@vsb.cz,vit.pasker@vsb.cz, robert.hlavica@vsb.cz, pavel.foretnik@vsb.cz

https://doi.org/10.37904/metal.2020.3634

\begin{abstract}
The article deals with using computational method and digital filters in power grid quality analysis in metallurgical industry. Almost all of metallurgical factories using large engines, arc furnace, induction heating and so on. This amount of non-linear loads which are connected to power grids cause heavy disturbances, which can cause big problems like damage or even destruction of machines or devices connected near the point, where disturbances occur, for examples near cities. Identification of disturbances is then very important for elimination of these problems. The article describe usage of digital filters which are applied on measured signal from power grid. Using these types of digital filters is necessary for identification problem in power grid.
\end{abstract}

Keywords: Metallurgy, power grid, integration, digital filters

\section{INTRODUCTION}

When the signal from power grid is measured it is necessary adapt this measures signal for next processing. Digital filters are one of many tools how to adapt measured signals. Thank to development of microprocessors, especially 32 bit microprocessors it is possible implement this digital filter direct in code for microprocessor. Computing power of todays microprocessors give enough power to execute these digital filters immediately after measuring signal. In this paper are described appropriate digital filters for processing measured signal from power grid in metallurgical factory.

\section{PROBLEM ANALYSIS}

Digital filters are very popular and at the present time there are many ways how to realize them. This paper introduce several algorithms, which can substitute some hardware filters for measurement purposes. Digital filters are far more scalable than the hardware ones. On the other way, implementing into microprocessor unit is relatively difficult and it is needed some skills to build them. The first approach to use digital filters instead of hardware ones is to choose proper filter type. In this chapter will be introduced several variants of digital filters and its impact to input signal.

The input signal has in principal sinusoidal running with main frequency of $50 \mathrm{~Hz}$ and many superimposed frequencies. The goal is to obtain clear sinusoidal like signal running to compute its RMS (Root Mean Square) value, inflection points and so on. Inflection points are very important, if it is needed, for example, to control semiconductor power switch. The first algorithm for filtering discrete signal was used FIR (Finite Impulse Response). Its formulation is in equation (1).

$F I R_{n}=\sum_{i=1}^{n} \sum_{j=1}^{m} \boldsymbol{h}_{j} \cdot n_{i}$

where:

$F I R_{n}$ - output filtered signal 
$\boldsymbol{h}_{j}$ - impulse response vector

$n$ - current sample

$j$ - length of impulse response vector

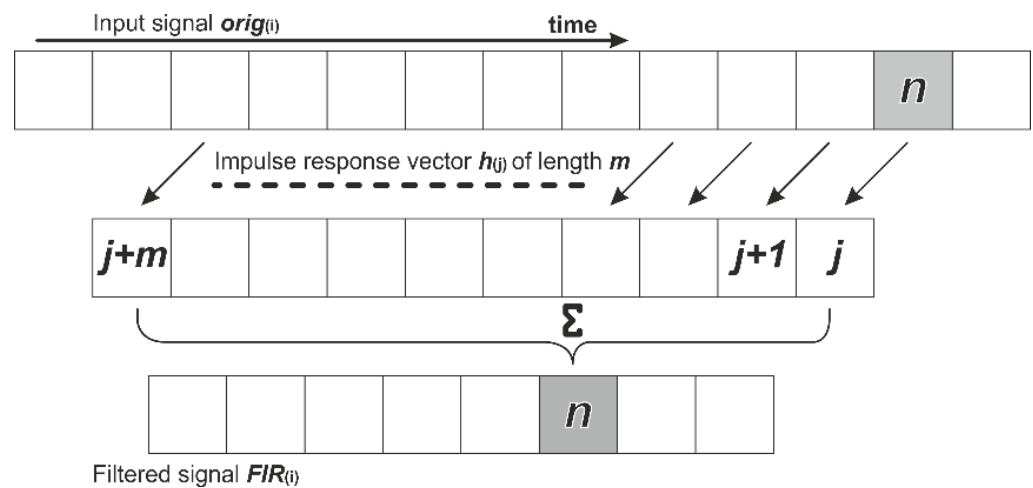

As can be seen in Figure 1 the $n$-th sample of original signal (origi) is multiplied by impulse response vector and the results are summed into new signal sample $F I R_{i}$.

Figure 1 Principle of FIR filter algorithm process [own study]

Impulse response vector can be obtained from initial DFT (Discrete Fourier Transformation) processing, or alike. There are many suggestions, how to setup $\boldsymbol{h}$ vector. The calculation itself has relatively high overhead and without optimization cannot be implemented into cheap MCU [1-5].

On the FIR filter idea basis was developed and tested AVG algorithm. The idea is similar to FIR, but the final vector is averaged. Its formulation is in equation (2).

$A V G_{n}=\frac{\sum_{i=1}^{n} \Sigma_{j=1}^{m} w_{j} \cdot n_{i}}{\operatorname{lng} t}$

where:

$A V G_{n}$ - represent output filtered signal

$\boldsymbol{w}_{\boldsymbol{j}}$ - history influence vector

$n$ - current sample

$j$ - number of historical samples used for averaging

Ingt - length of sampled data

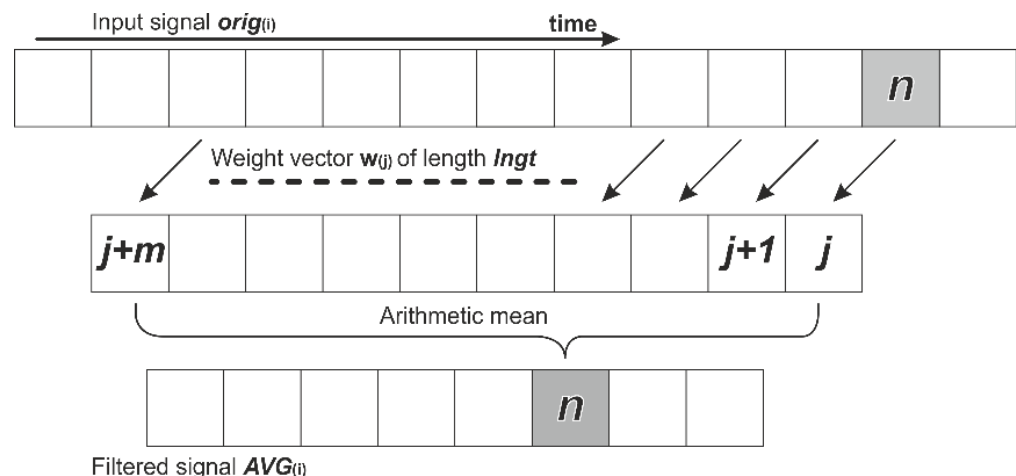

Filtered signal $\boldsymbol{A} \boldsymbol{A} \boldsymbol{G}_{(\mathbf{i})}$

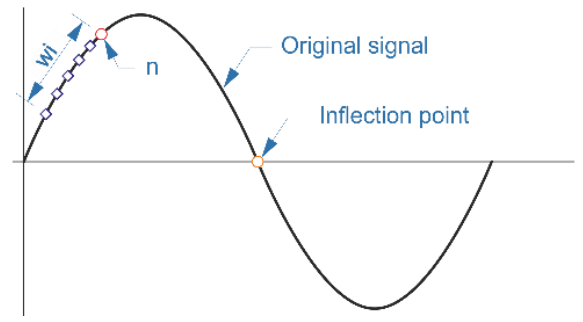

As presented in Figure 2, the current sample of original signal origi is multiplied with historical influence vector which represent the historical influence. The whole vector is averaged and this value create new sample of filtered signal $A V G_{i}$. This algorithm has good results and require slightly less $\mathrm{MCU}$ overhead.

Figure 2 Principle of AVG filter algorithm [own study] 
Besides of two presented algorithms were tested also two simple integration algorithms. The first one use simple representation, presented in equations (3) and (4) [6-10].

$$
e=\frac{I N T_{i-1}-\text { orig }_{i}}{\text { step }}
$$

where:

$e-$ is simple deviation

$I N T_{i}-i$-th sample of filtered signal

orig $_{i}$ - $i$-th sample of original signal

step - constant, dependent on sampling rate

$I N T_{i}=I N T_{i-1}-e$

where:

$e-$ is simple deviation

$I N T_{i}-i$-th sample of filtered signal

The final sample of filtered signal is calculated by subtraction of $e$ from the $i-1$-th sample of signal INT.

The second one use historical deviation value. The history depth can be varied to obtain better results according to the signal behavior, or sampling rate. The calculation process is presented in equations (5), (6) and (7).

$e_{1}=\frac{I N T_{i-1}-o r i g_{i}}{\text { step }}$

$e_{2}=\frac{I N T_{i-k}-o r i g_{i}}{\text { step }}$

$I N T_{i}=I N T_{i-1}-\frac{\left(e_{1}+e_{2}\right)}{2}$

Where:

$e_{2}$ - deviation of $k$-th sample from the past

$I N T_{i-k}-i-k$-th sample of filtered signal

The final sample of filtered signal is calculated by subtraction of averaged e's from the $i$-1-th sample of signal INT. This variant of integral algorithm has better results in some cases of original signal [5].

The all four algorithms mentioned in text above are presented in Figure 3. The original signal is $50 \mathrm{~Hz}$ artificial sinusoidal signal with superimposed $250 \mathrm{~Hz}$ and $2000 \mathrm{~Hz}$ smaller sinusoidal signal. The all four filtered signal has phase shift, which is undesirable and has to be corrected. As can be seen on the same figure, there were implemented algorithm to find inflection points in original signal. For this purpose were calculated first and second derivation ( $y$ ' and y") and where the curve of second derivation pass zero level where marked inflection points. The computational demands were for presented signal are $2.985 \mathrm{~s}$ for FIR, $2.714 \mathrm{~s}$ for AVG, INTEGRAL $_{1} 0.08 \mathrm{~s}$. and INTEGRALL $20.014 \mathrm{~s}$. The computational differences are vital [11-15]. 

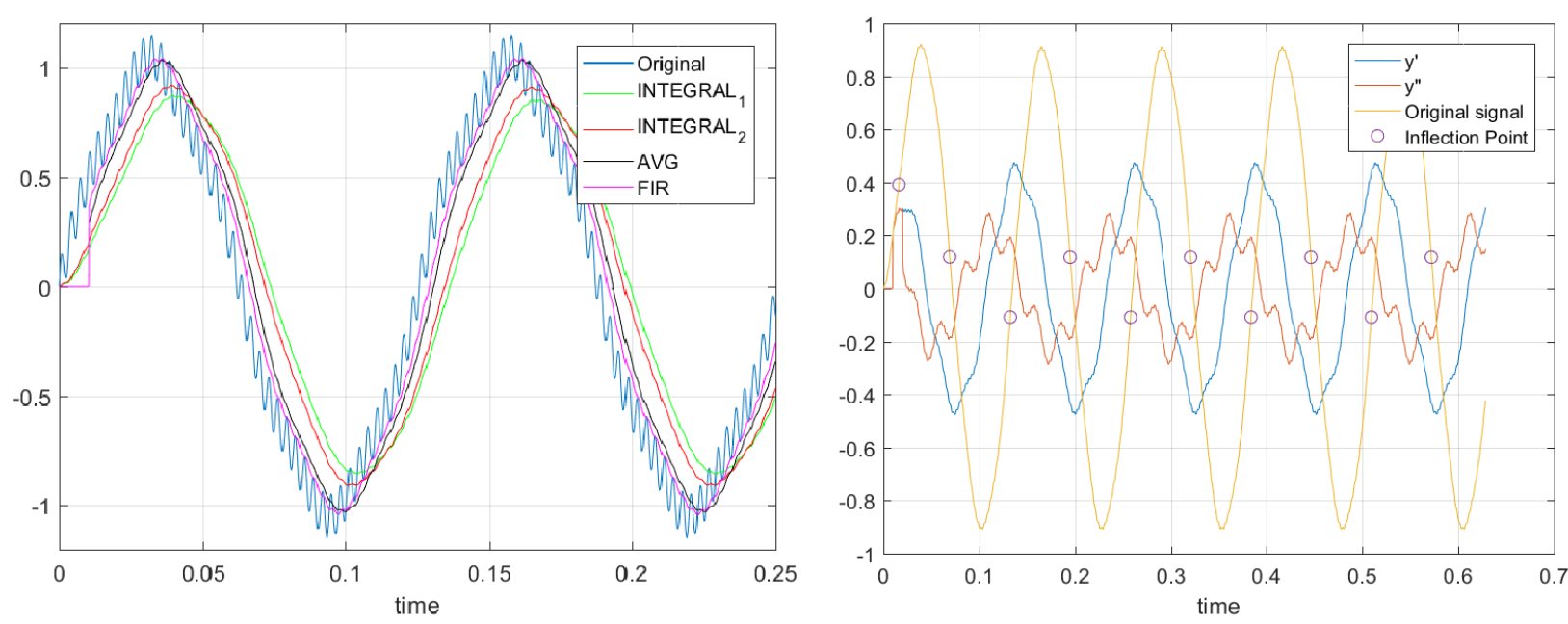

Figure 3 The original signal and four tested filtering algorithms [own study]

\section{CONCLUSION}

Replacement of hardware integrator device by filtering algorithm in microprocessor is not a simple task. As were presented, there are many algorithms with various impact on filtered signal, with various computing demands, which can be used. This research is only the initial step, before the real software digital filter will be developed. For energy measurement purposes will be most probably suitable integration like algorithm, which has good results and very low computational demands. It will be necessary to express overall error before next advance can be done. Tests of measuring were carried out near metallurgical factories in Ostrava and Katowice. In this measured values is large THD which can affect classical measuring of power. On these measured values was applied digital filters and even with large values of THD precision below $0,5 \%$ has been achieved.

\section{ACKNOWLEDGEMENTS}

The work was supported by the specific university research of Ministry of Education, Youth and Sports of the Czech Republic No. SP2020/18, SP2020/61 and RPP2020/136.

\section{REFERENCES}

[1] LELAND, J.B. Digital Filters and Signal Processing: With MATLAB Exercises, 3rd Edition. New York : Kluwer Academic, 1996.

[2] DASH, J., DAM, B., SWAIN, R. Design of multipurpose digital FIR double-band filter using hybrid firefly differential evolution algorithm. Applied Soft Computing. 2017, vol. 59, no. 8, pp. 529-545.

[3] TREICHLER, J. Notes on the Design of Optimal FIR Filters. Houston: Rice University, 2009.

[4] ZAHOOR, S., NASEEM, S. Design and implementation of an efficient FIR digital filter. Cogent Engineering. 2017, vol. 4, no. 2, pp. 1.

[5] FRISCHER, R., DAVID, J., SVEC, P., et al. Usage of analytical diagnostics when evaluating functional surface material defect functional surface material defects. Metalurgija. 2015, vol.54, pp. 667-670

[6] SVEC, P., FRISCHEROVA, L., DAVID, J. Usage of clustering methods for sequence plan optimization in steel production. Metalurgija. 2016, vol.55, pp. 485-488.

[7] BOUKHAROUBA, Abdelhak. Smoothed Rectangular Function-Based FIR Filter Design. Circuit systems and signal processing. 2017, vol. 36, no. 11, pp. 4756-4767.

[8] COSTA, A., GEORGIDIS, D., NG, TS., SIM, M. An optimization model for power grid fortification to maximize attack immunity. International Journal of Electrical Power \& Energy Systems. 2018, vol. 99, pp. 596-605. 
[9] SATPATHI, K., YEAP, YM., UKIL, A., GEDDADA, N. Short-Time Fourier Transform Based Transient Analysis of VSC Interfaced Point-to-Point DC System. IEEE Transactions On Industrial Electronics. 2018, vol. 65, iss. 5, pp. 4080-4091.

[10] LIU, YK., XU, X. Industry 4.0 and Cloud Manufacturing: A Comparative Analysis. Journal of manufacturing science and engineering-transactions of the asme. 2017, vol. 139, no. 034701, pp.10-20.

[11] SVEC, P., FRISCHEROVA, L., DAVID, J. Usage of clustering methods for sequence plan optimization in steel production. Metalurgija. 2016, vol. 55, pp. 485-488.

[12] KREJCAR, O. and R. FRISCHER. Real Time Voltage and Current Phase Shift Analyzer for Power Saving Applications. Sensors. 2012, vol. 12, no 8, pp. 11391-11405.

[13] SEIDL, D., KOŠTIAL, P., JANČíKOVÁ, Z., RUŽIAK, I., RUSNÁKOVÁ, S., FARKAŠOVÁ, M. Modal analysis Measurements versus FEM and artificial neural networks simulation. Communications in Computer and Information Science. 2011, vol. 188, issue PART 1, pp. 170-175.

[14] KOIWA, K., LIU, KZ., TAMURA, J., Analysis and Design of Filters for the Energy Storage System: Optimal Tradeoff Between Frequency Guarantee and Energy Capacity/Power Rating. leee Transactions On Industrial Electronics. 2018, vol. 65, pp. 6560-6570.

[15] DAVID, J., POLLAK, M., TUHY, T., PRAZAKOVA, V. Modern communication technologies usage for controlling metallurgical processes. In METAL 2014: 23rd International Conference on Metallurgy and Materials. Ostrava: TANGER, 2014, pp. 1678-1683. 